\title{
Patrimonio: la evolución de un concepto voluble en un mundo globalizado
}

María Antonia Garrido Martínez | conservadora de patrimonio y museos y asesora de patrimonio y arqueología de la Junta de Comunidades de Castilla-La Mancha

URL de la contribución <www.iaph.es/revistaph/index.php/revistaph/article/view/3886>

El concepto de patrimonio es voluble, ha cambiado a lo largo de la historia, en función del territorio, según qué cultura, contexto socioeconómico, nivel educativo-cultural de la sociedad que lo define y lo defiende, trayectoria político-proteccionista del país... Acostumbrados como estamos a ver el mundo con los prismáticos occidentales, es evidente que no puede ser igual el concepto que se tiene de patrimonio aquí o en Pekín, por mucho que se hayan establecido directrices internacionales al respecto. Al contrario de lo que pudiera parecer a priori, esta variabilidad de puntos de vista enriquece el término sobremanera. Es, por tanto, positivo para afinar en su concepto. De hecho, patrimonio indica posesión adquirida o heredada e incluso creada ex novo. La idea de pertenencia es intrínseca.

Como reconocimiento reglado de estos cambios conceptuales, ha pasado a considerarse lo "cultural", en nuestra normativa, sobre lo tradicional "histórico", característica que se le ha venido atribuyendo sine qua non. $Y$ es que los valores que se le adjudican al patrimonio también han evolucionado. El mundo globalizado unifica de tal manera a los seres humanos de culturas radicalmente diferentes que, como efecto resorte, surge en el mismo la necesidad de identidad individual.

La masa informe de la globalización diluye e iguala. Esto hace que, consciente o inconscientemente, nos apropiemos de elementos culturales definitorios de otras comunidades y que suceda lo mismo en sentido inverso. Gran parte de la ampliación del concepto se justifica por la búsqueda del ser humano de sus raíces, de su identidad, de lo que lo desdibuja y singulariza, vinculado con su territorio más directo. De ahí la valoración en los últimos tiempos del patrimonio etnológico e inmaterial o el contexto paisajístico e incluso el paisaje en sí mismo.

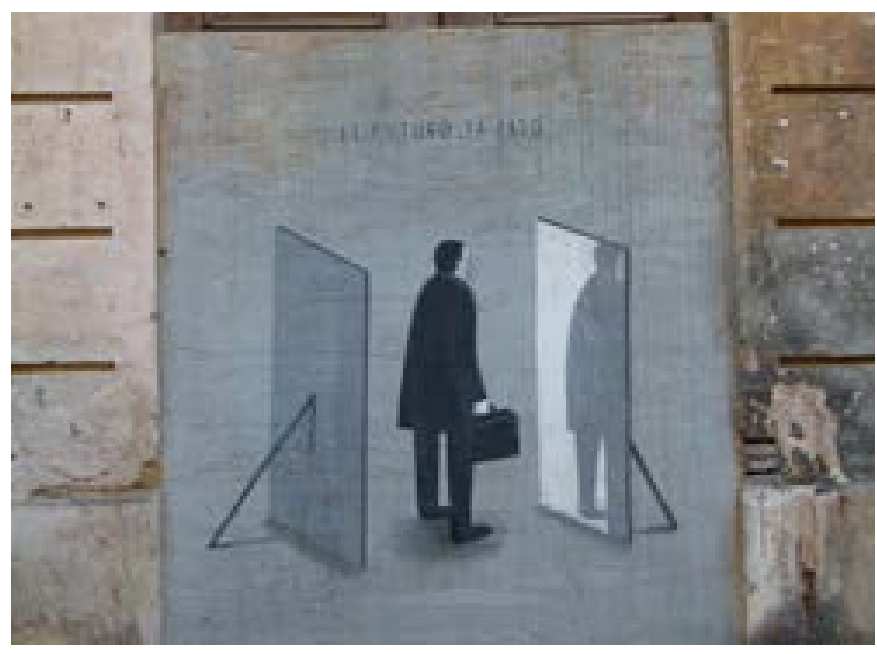

El futuro ya pasó. Arte Urbano en Valencia | foto Antonio Martín Segovia

Efecto de la globalización, igualmente, es la crisis económica mundial en la que nos encontramos desde hace prácticamente una década. Ésta imprime homogeneización a las circunstancias socioeconómicas a nivel internacional, lo que ahonda aún más en la necesidad humana de sobrevivir al desastre común buscando referentes más sólidos, estables, menos cambiantes y más auténticos. Facultades achacables al patrimonio cultural. La humanidad actualmente ha encontrado en lo cultural su esencia y, en sus múltiples manifestaciones, el sentido perdido de la existencia.

El patrimonio cultural está formado por una acumulación de creaciones y transformaciones humanas y naturales que cuentan mucho de nosotros, lo que contribuye a valorar las emociones que trasmite como extraordinarias y dignas de protección y conservación, para que no se pierdan, puedan ser disfrutadas por nuestros descendientes y puedan ser ampliadas, enriquecidas y aprovechadas por nosotros y por los que vengan. 
a debate Visiones patrimoniales para definir el objeto del siglo

| coordinan José Ramón Moreno Pérez, Marta García de Casasola Gómez

El documento de Nara (UNESCO, ICCROM e ICOMOS) de 1994 contribuyó a recoger la importancia de la autenticidad que debe trasmitir el patrimonio. Lo genuino, lo irrepetible. En un mundo donde prácticamente todo es reproducible, lo auténtico es uno de los valores añadidos más importantes que el patrimonio posee. Pero no por ello inamovible. Las técnicas constructivas tradicionales, por ejemplo, tienen mucho que aportar en el mundo moderno, lo que no implica que se deje de investigar en nuevos materiales y sus aplicaciones. Es nuestra obligación conservar y preservar las construcciones históricas, los estilos, técnicas, saberes y conocimientos que de ellas se desprenden para que, sobre esto, podamos avanzar obteniendo resultados más óptimos.

De igual manera se comporta la creación pictórica o escultórica. La evolución de soportes, materiales, estilos, modas a lo largo de los tiempos no hace más que enriquecer la creación actual, que no sería lo que es si no hubiese existido previamente lo anterior. Los oficios artesanos, las fiestas tradicionales tampoco están exentas de evolución, y así han prosperado y se han perfeccionado, por lo que no sería justo impedir que progresen, se adapten y se reutilicen hoy en día. Se trata de no adulterar el mensaje. Cuando conservamos, nuestra presencia ha de ser lo más volátil posible. Hacer estrictamente lo necesario para que el bien continúe viviendo. Es por esto que nuestra participación en el proceso no debe torcer todo lo que de documento tiene cualquier bien patrimonial. En teoría, puede estar claro y más o menos asumido. La práctica es otra cosa. Hemos participado en la rehabilitación de edificios para usos actuales en los que han sido imperativos los cambios; en la puesta en valor de yacimientos arqueológicos; o en la restauración de bienes muebles cuyo destino y uso difiere del original para el que fueron concebidos. La conservación de la autenticidad es difícil, pero debemos tender hacia ella en cualquiera de las adaptaciones a las que se ven obligados nuestros tan preciados Bienes Culturales, en mayúsculas.

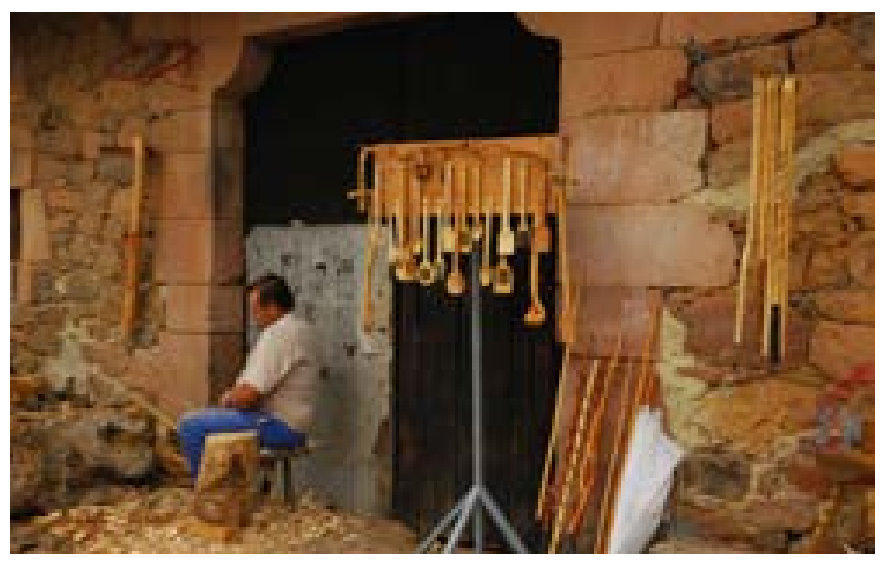

Artesano en Carmona (Sevilla) | foto Henar Lanchas

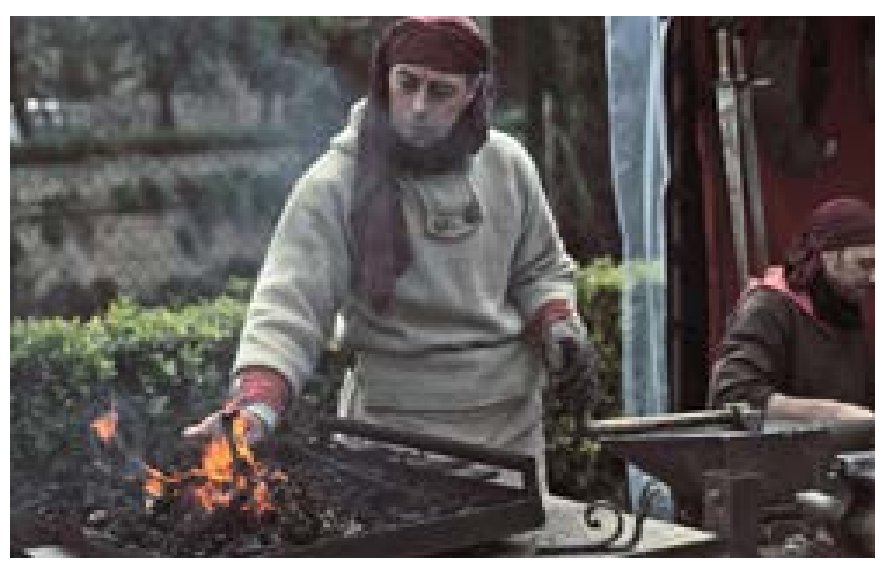

Los antiguos oficios no se han perdido del todo. En las ferias medievales aún se pueden encontrar artesanos | foto oitaven_Arcade

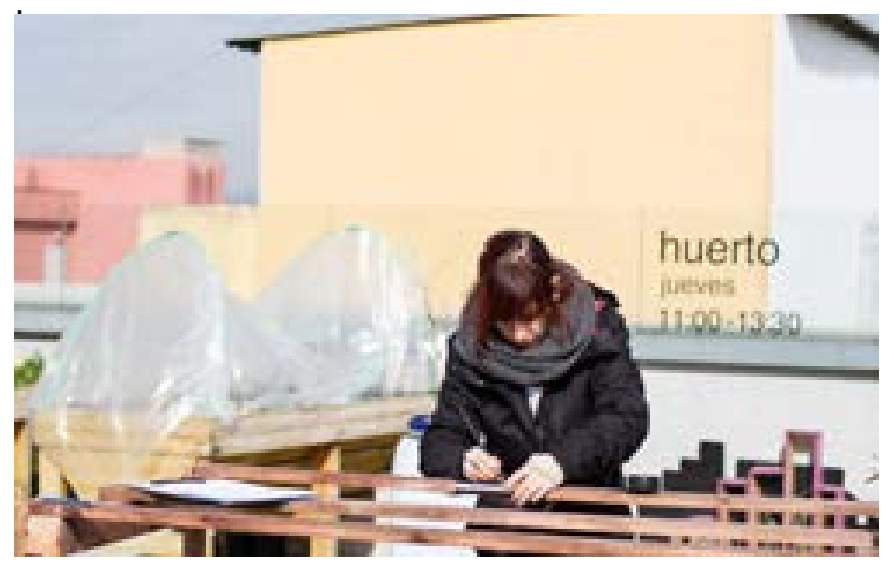

Huerto en la terraza del CA2M (Madrid). Taller de construcción de mobiliario para el huerto | foto Centro de Arte Dos de Mayo 